\title{
Organization and conflict
}

\section{KENNETH E. BOULDING}

University of Michigan

This paper concentrates on the problem of the "parties" to conflict. Every conflict involves at least two parties or conflicting organizations. The party may be a biological individual, or it may be an aggregate or an organization of individuals. All individuals are organizations of subordinate parts: all organizations are in some sense "individuals" insofar as they have well-defined patterns of behavior and reaction. Cenerally, we may wish to reserve the term "competition" for the wide concept which includes interactions among unorganized aggregates (such as biological populations) and to use the word "conflict" for the narrower concept in which the conflicting parties are individuals or organizations, possessing a certain core of unity of behavior and in which each organization is in some sense "aware" of the other and makes this awareness an essential part of its behavior pattern. We think of conflict, then, as a system of interacting systems, each party to the conflict being a system in itself, bound, however, to the other party by a system of communication, information, subjective knowledge, and behavior reactions. The question as to what property of such a system constitutes the "conflictual" as opposed, say, to the co-operative element is surprisingly difficult to answer and will be considered later.

\section{A Model of Organization as System}

Let us consider first, then, the nature of the systems which are involved in an organ- ization. What we want here is not the organization in all its richness and completeness but rather the most simple abstract model of an organization which will serve to illuminate the relationships between organizations. An organization, we may recall, may include things as complex as an amoeba or as simple as the General Motors Corporation! What we are looking for here is the simplest model which will enable us to study the interaction of organizations.

The first element in the description of an organization is a static structure of partsits geography or anatomy, its organization chart or balance sheet or molecular structure. There are very interesting elements of scarcity or competition even in these static structures which may sometimes underlie conflicts-in a sense, all conflicts of interest, or "issue conflicts," arise because two things cannot be in the same place at the same time. Everything cannot be close to everything else; there is an inexorability about geography and topology which necessitates more separation of parts in large structures than in small and which imposes limits on the growth of any particular type of structure. Thus in a triangular lattice each individual part can be in direct contact with no more than six others. Fundamental also in limiting the size of organizations is the scale model, or D'Arcy Thompson principle (5), that the increase in size of a structure inevitably brings with it a change in the ratio of lengths to areas and volumes. Doubling linear dimensions of a structure quadruples 
its areas and octuples its volumes and hence diminishes the relative importance of those properties which depend on length (such as communications) or on area (muscular or structural strength, absorption of air or food) to those which depend on volume (weight). Hence we get the very important principle that if the relative importance of linear, areal, and volumetric properties are to be preserved, the form of the structure must change as it increases in size; there must be elaborations of linear networks (nerves and channels of circulation); there must be convolution of areas of surface reaction (lungs, brains, bowels), in order to increase the ratio of linear or areal dimensions to volume and weight. In social organizations (firms, states, universities), communications networks and specialized administration must increase their relative importance as the size of the organization grows.

The next step in the development of an organization model is its description as a "machine," or energy transformer. Any organization depends on some source of energy for its continued existence-food and light in the case of the biological individual, to which may be added coal, oil, and other sources in the case of manufacturing plants or armed forces. Scarcity of energy sources may be an important source of competition and issue conflict, for what is taken by one organization may be taken from another. Where the game against nature results in a "victory" and the release of another source of energy, the possibility for the expansion of all organizations together emerges, and the conflict between them is at least temporarily lessened. Surprisingly little attention has been paid to the general description of the energy requirements of social organizations. The basic source of energy for such organizations is the same as that for the in dividuals of which they are composed-food. The surplus of food production over and above the consumption of the agriculturalist is perhaps the best index of the ability of a society to construct social organizations of all kinds. Savage societies cannot develop complex organizations because the food producer must spend all his time getting enough for himself and his family. In the United States today we can produce all the food we need with 10-15 per cent of the population and so release up to 90 per cent of the population for "other things."

\section{ORGANIZATION GROWTH}

\section{AND CONFLICT}

The next step in the organization model is to describe it as an "open system" or, more generally, as a "growth system" or dynamic open system. A static open system is a structure which is maintained in the midst of a stream or throughput of its constituent parts. To be an open system, a structure must have the property that a "hole" in the structure produces a large attractive force or valency to pull an appropriate "occupant" from the surrounding environment into the "hole." Thus a living organism maintains its structure more or less intact in the midst of a constant throughput of atoms of matter. A social organization is a structure of "roles": any vacancy in the role structure-i.e., any role without an occupant-creates pressure to fill the vacancy with an appropriately skilled person. It is this property of being an open system which enables organizations to live longer than any of their parts-presidents, deans, and professors come and go, but the university goes on forever.

In a dynamic open system there is not merely maintenance of an existing structure but growth (or decline) in the structure itself. Not only are old jobs filled as their previous occupants pass on, but new jobs are created. The atoms in a cell, the cells of the body, can likewise be regarded as a role structure subject to a constant throughput, in which new roles are constantly added as 
the organism develops from the egg. The laws of development of organizations are very imperfectly understood, and this is perhaps one of the most serious gaps in our knowledge. It is clear that development never takes place haphazardly, except perhaps in pathological cases such as a cancer. Certain "organizers" of development can be identified-the gene, the chemical organizers of the embryo, the entrepreneurs, the prophets, and the heroes who are the founding fathers of social organizations. How the organization of development is actually accomplished, however, is a great mystery, and our ignorance of this machinery is evidenced by our inability to predict outcomes, except after the event. We know that an acorn grows into an oak and never into a cactus, but just what it is in the acorn which gives it this remarkable property we do not know. Similarly, we do not know what mysterious property enabled the little group of Apostles to grow into the Christian church or the little group around Hitler to grow into the Nazi state, when thousands of similar groups perish in early infancy.

Although the processes of growth remain mysterious, we do know something about the factors which limit growth, and this enables us to make some significant propositions in the theory of conflict. An important source of conflict among organizations is the attempt of two or more organizations to expand into the same field. When two firms are expanding into a limited market or two nations into the same territory or two labor unions into the same job jurisdiction, a conflict of interest is likely to arise. This "expansion conflict," to coin a term for it, has both a static and a dynamic aspect. It arises in a static sense if the number of role occupants is limited, so that, as more are drawn into one organization, fewer are available for others-the more Rotarians there are, the fewer Lions and Kiwanians; the Methodist church may grow at the expense of the Baptist; and so on. We think of the whole field of organizations as dividing among them the raw material in the shape of members, much as nations divide up the geographic area of the world, and an expansion of one inevitably means a contraction of others, unless, of course, the field itself is growing. Growth in the field itself has thus an important effect in lessening the intensity of expansion conflicts. Thus in the nineteenth century the fact that so many European countries were able to expand their power and influence in. colonial empires outside Europe may have lessened the conflict among them; the closing of the colonial field in the early twentieth century may have been one reason for the two world wars. When the labor movement is expanding and all unions are organizing the unorganized, jurisdictional disputes between them lessen in intensity; when the field is closed and one union can expand only at the expense of another, these disputes increase in intensity. An era of great missionary activity, when the churches, too, are organizing the unorganized throughout the world, also sees the decline of denominational tensions and the rise of the ecumenical movement.

We must not apply the foregoing principle too mechanically, of course. We may have a situation where something like an equilibrium or balance of power has been reached in a static situation which is completely upset by the sudden development of opportunities for expansion. Organizations which have accepted a static situation now may find themselves with opportunities for growth. The opportunity creates a habit, and the organization which has developed a habit of expansion may not be content with expanding into defenseless and unorganized regions but may turn against other organizations like itself. Thus conflict depends on what might be called the "expansion pressure" of organi- 
zations, as well as on the nature of the opportunities which surround them. We might, therefore, identify three extreme cases. First is the situation in which the environment is static, in the sense that there is no expansion of the "raw material" of organizations, but in which there is little or no conflict because the organizations which occupy the field have no expansion pressure, are content to be stationary, and simply reproduce themselves without growth. The second case is that in which there is expansion pressure but in which there are abundant opportunities for the growth of each organization through the growth of the field itself. In this case, also, there will be little in the way of expansion conflict, as the organizations are expanding into an empty or unorganized field rather than into each other. The third case is that in which the field is static or expanding very little, but the organizations have great internal expansion pressure. Here conflict will be intense, as each organization can expand only at the expense of others of like propensities. We might perhaps distinguish a fourth case, of which the first case mentioned above is a special example, in which some organizations are expanding and some contracting in a static field but in which the contracting organizations do so willingly. In this case the expansion pressures and "contraction pressures" cancel out, and there is again little or no conflict. ${ }^{1}$

1 These cases can be formalized into a mathematical measure of expansion conflict. Suppose we have $n$ organizations, occupying a field of size $X$, apportioned among them in amounts $x_{1}$, $x_{2}, \ldots, x_{n}$. Suppose that each organization has a desired rate of growth (or decline), $r_{1}, r_{2}, \ldots$, $r_{n}$. Let $R$ be the rate of growth of the whole field. Then expansion conflict potential may be measured by the expression

$$
C=r_{1} x_{1}-R X .
$$

If the aggregate desired rate of expansion is equal to the actual rate of growth of the whole

\section{INFORMATION, KNOWLEDGE, AND}

\section{ORGANIZATION IMAGE}

Now, if we are to explore further the nature and determinants of expansion pressure, we must go to a fourth level of organization theory. This is the level of control processes involving information inputs and outputs and knowledge structures. The simplest model here is that of a cybernetic or homeostatic process, where we assume that there is a variable or, more generally, a set of variables which the organization is concerned to maintain at some equilibrium values. These variables must be in the information input of the organization, at least to the extent that the organization "knows" when there is a divergence of the value given by the information input from the ideal value which the organization sets out to maintain. This knowledge is reflected in behavior or action of some kind directed toward correcting the perceived divergence between the real and the ideal values of the homeostatic variables. For a system like this to operate successfully, there should also be "relational feedback"-that is, information regarding the divergence between real and ideal and especially regarding the change in this divergence, which is perceived as related to the action taken.

The theory of organizational behavior which is implied in this model might be described as the epistemic or "eiconic" theory (1). It postulates that any organization

field, expansion conflict potential will be zero. If the aggregate desired expansion is greater than the actual growth of the field, there will be conflict: $C$ will be positive. The greater the excess of the aggregate desired expansion over the growth of the field, the greater the potential for conflict. Negative values of $C$ are not particularly signifcant and simply indicate no conflict. This is the situation where the expansion pressure of the organizations is so small that they reach their equilibrium sizes without even exhausting the available field. 
possesses as part of its essential structure a "view of the universe" or "image" (hence the term "eiconic"). This image has many dimensions. In man, for instance, it involves a view of space and time and his position in them; it involves a relational image of cause and effect and connection; it has dimensions of reality and unreality, publicness and privateness, certainty and uncertainty, emotional effect; and over the relevant part of the field there is a value ordering according to which one part of the field can be identified as "better" or "worse" than another part. Behavior or action is then interpreted as the initiation of a cause-effect process which will move the organization toward the most highly valued part of its image of the future. Here, for instance, is a man who gets up in the morning, dresses, shaves, has breakfast, and takes a plane to New York. In explaining the behavior of this aggregation of some ten billion cells, we must postulate that he has a view of the spatial universe which includes at least his own bathroom, dining room, and the way to the airport and in which, in spite of the agreeableness of staying in bed, moving into the bathroom and scraping his face with a razor are valued at the moment more highly than anything else which he might be doing. Similarly, he goes to New York rather than to any one of a hundred other cities because it is for him at that moment the most highly valued part of the attainable surface of the earth-for what further reason we need not inquire.

This view of behavior then raises a number of questions regarding the subordinate processes which are involved even in the simplest behavior. These concern themselves mainly with how the image, in all its complexity, is built up and especially how messages which are received by the organization result in a change in the image, for it is only through a change in the image that there can be a change in behavior. The image is not, of course, simply a pile or aggregate of messages. Most messages which are received make little or no impression on the image, or they merely serve to confirm an existing image. As I turn my head, a new message enters my eyes; it merely serves, however, to confirm the image that I am sitting in a room typing. Frequently, messages are received which merely add to the image without appreciably changing its structure; the processes of rote learning are a good illustration. Sometimes, however, a message is received which effects a revolution or reorganization of the image. A man is informed that he is promoted; this changes his image of his own role and person. A man receives overwhelming evidence that his trusted friend has deceived him; this changes his image of his friend's personality. A nation undergoes a revolution; this changes the image of the character and probable behavior of the nation, both in the minds of its own people and in the minds of others.

It is the peculiar glory, and occasionally the shame, of man that his images are built up not only by the receipt of messages from nature (signs) but also by the receipt of symbolic messages, proceeding directly from other persons in face-to-face contact or indirectly through the medium of "transcripts" -books, papers, records, movies, television, and so on. Man is the talking animal, and the complexity of his organizational world depends largely on his ability to communicate in symbols. If I hear a voice behind me, I may interpret this information as indicating the presence of a person, and the character of the voice will give me clues as to the character of the person-whether it is familiar or unfamiliar, foreign or native, male or female, etc. So far, the voice is merely a sign; it does not matter what words are spoken, and the process of building this information into an image is not essentially different from the process by which any 
other message from nature conveyed by any of the senses is built up into an image of the world around us-a world of rocks, trees, clouds, animals, people, buildings, and so on. The moment, however, that words are spoken which are understood, we pass to a "higher" and immensely complex system of symbolic communication which has the property of building up images far removed from the immediate world around us. Symbols remove the human organization from the prison of the immediate here and now, in which all lower forms of life are trapped, and the image of man therefore soars off to the galaxies, to the beginnings and the end of all things, to the realm of the impossible and almost to the inconceivable. It is because of this symbolic nature of the image of man that conflict in the human world is so much more complex than conflict in the animal kingdom, where images are built up only by signs and hence conflict is always face to face.

\section{VALUE DIMENSIONS OF THE ORGANIZATION IMAGE}

The theory of the image points to another problem underlying any theory of behavior and interaction-the problem of the determinants of the value image or, more accurately, the value dimension of the image. This is vital for a theory of behavior, for, as we have seen, behavior consists of movement into the most highly valued part of the total image. A shift in the value ordering, therefore, even without any change in the rest of the image, can produce profound, even revolutionary, changes in behavior. I may be all set to get on a plane for New York when I receive a telegram to say my father has died in San Francisco; the information creates a marked shift in my valuation of my image of space and time: I cancel my reservation to New York and get a plane to San Francisco immediately because this is now the most highly valued part of my image of the world of space and time. Note that the value ordering is not the same as the emotive or pleasure-pain dimension of the image; my engagement in New York may have been perceived as very pleasant, whereas my task in San Francisco may be very painful. The value ordering, however, is capable of overriding all other orderings, and it is the value ordering which dominates behavior. Notice that in this case there is no change in my general image of space and time-I still visualize New York and San Francisco as occupying the same relative positions on my inner globe. In this example we might argue that it was a change in my detailed image of space and time, especially of persons, which caused the change in the value image; thus I now visualize my father as dead, whereas previously I had visualized him as alive. We cannot always assume, however, that it is changes in some other aspect of the image which causes a change in the value image. There may be revolutions in the value image which are quite independent of any change in the rest of the image. I am asked, for instance, do I prefer tea or coffee. I say tea, and then immediately "change my mind" and say coffee. My images of tea and coffee remain the same; only my value ordering has changed.

We cannot say very much, perhaps, about so general a matter as the forces which determine the value ordering over the life of an individual. These orderings certainly originate at the biological or presymbolic level. Even though the value ordering cannot be identified with any pleasure-pain ordering, it is clear that the sheer force of natural selection produces innate value orderings which are conducive to survival and that the low positions in the value ordering which are generally given to cold, hunger, thirst, sexual abstinence, and pain are not wholly accidental. Once the symbolic image is in- 
troduced, however, value orderings share in the almost unlimited proliferation of the image which symbolic messages induce, and the biological origins are transcended and transformed often out of recognition. For his symbols man has been willing to endure any amount of physical discomfort and pain, even to the point of death.

In considering the value image and, indeed, the image in general, attention should be drawn to the importance of stereotypes, or what might be called condensed images. These arise mainly because the human organism, beyond a certain point, places lower and lower values on increasing complexity in the image, probably because of some limitations of capacity in the underlying biological structure. We therefore seek escape from complexity into simple, unitary condensed images. This is especially important in regard to the value image, where complexity rapidly becomes intolerable, and we constantly seek straightforward ordering. We try to divide the world into "good guys" and "bad guys" (it is unquestionably the simple value structure of the horse opera which gives it so universal an appeal). Similarly, we divide the world into "peace-loving nations" and, presumably, war-loving nations, and we divide people into simple pejorative dichotomies-Jews and gentiles, white and Negro, believers and unbelievers, the scientific and the superstitious, and so on, to the horror of the semanticist and the great confusion of man. We cannot rest content with propositions of the form " $A$ is better than $B$ in respect to $X$, but worse than $B$ in respect to $Y$." We want to know where $A$ is altogether better or worse than $B$. So we run to grade sheets; cost-of-living indexes; national, racial, and occupational stereotypes, in an attempt to escape from the intolerable multidimensionality of reality. Up to a point this simplification is a necessity-we could not act at all were we not capable of effect- ing these drastic condensations of the image. Condensation, however, can easily become pathological and may be an important cause of conflicts which could be resolved if the parties had a greater tolerance of complexity and ambiguity.

The danger to organizations and to the harmony and fruitfulness of their interactions, which comes from condensation of the image, arises from what might be called the principle of linked homeostasis. Suppose that there are two variables which must be maintained within the limits of homeostatic tolerance. If the mechanisms by which each is stabilized are too closely linked, the stabilization of one may be achieved only at the cost of the de-stabilization of the other, or they may both be stabilized only with a range outside what is regarded as desirable for both taken separately. Thus suppose we wish to stabilize both the temperature and the humidity of a building. If the apparatus for maintaining these variables is linked, we may find ourselves in the position where an attempt to raise the temperature lowers the humidity, and we find ourselves forced to choose between the warm and dry or the cold and moist, and we cannot achieve the "ideal" of warm and moist. The linkage may occur anywhere in the system, either in the information receptors, in the "image" of the control, or in the effectors (furnaces and humidifiers) by which the variables are changed. One suspects that the main source of linked homeostasis in human systems is in the condensed image. Information about two or more essential variables is condensed in the image into a single variable and can produce only a single behavior reaction in the effectors. Thus the inability to discriminate leads, paradoxically enough, to discrimination in the sociological sense. We lump together in the image things which should be separate, and, because of this, we behave toward a heterogeneous reality as if it were 
homogeneous and toward a homogeneous reality as if it were heterogeneous. Thus we condense the immensely complex image of personality into a few stereotypes-"Negroes," "Jews," "eggheads," “capitalists"and classify those we meet immediately into these simple boxes and order our behavior accordingly, oblivious of the fact that our boxes are full of all kinds of different people, requiring different modes of behavior, and that a classification according to appropriate modes of behavior might be quite different.

Up to this point I have not emphasized the distinction between persons and organizations of persons, having simply a model of a "behavior unit" without regard to its composition. There are, however, important differences between the individual person as a system and a social organization, such as a university or a corporation. It is easy to fall into a mystique of organizations and imbue them with personality, motives, and patterns of behavior in a way that is at best a metaphor and at worst a serious misconception. In a literal sense, only persons can possess images, and only persons can behave. Nevertheless, there is a sense in which an organization can be regarded, in Ralph Gerard's terminology, as an "epi-organism," possessing as a system many of the system properties of organisms. Even in the strict biological sphere, it is not always easy to tell where an organism ends and its environment begins, and for some purposes whole ecosystems can be regarded as a single organism, exhibiting division of labor, exchange, homeostasis, and so on. In the case of the social organization, what gives it a unitary character or "personality" is the existence of widely shared images, especially of the organization itself, among the participants. One should perhaps say "integrated" images rather than "shared," as the images of different persons may be very different and yet may fit into a unified whole. Thus the image which the president of a university has of his institution is very different from the image of the same institution in the mind of the instructor, the gardener, or the accountant. Nevertheless, all these images fit together into a role structure and a perception of appropriate behavior which makes the institution operate with a degree of unity and consistency. The instructor does not spend all his time cutting the college lawns, nor does the gardener harangue students on abstruse subjects from the college podiums. All the various images must have something in common, however vague, and an inadequate common image is a frequent source of internal disorganization. The head of a department who cannot see beyond his own department, the professor who cannot see beyond his own classroom, and any employee who has no vision whatever of the institution beyond his paycheck are all potential sources of internal strife and weakness.

\section{ESTABLISHMENT AND DEVELOPMENT}

OF THE IMAGE

The question as to how common images are established is, therefore, a crucial one from the point of view of the theory of the social organization. The problem involves the dynamics of the change of the image under the stimulus of mainly symbolic messages. I am prepared to suggest as a very plausible hypothesis that common images are formed mainly through "conversation"that is, through a dynamic process by which messages are sent back and forth among a group of people. The basic unit of conversation is the "remark." A remark always proceeds from the image of the remarker. It is heard by listeners and modifies the image of the listeners, unless there is strong resistance, in the direction of the image of the remarker. In conversation the listeners in turn become remarkers, and the images of the different individuals converge as each 
modifies the other in the direction of his own. For this to happen, however, I suspect that there must be a certain degree of initial similarity in the images. If the images are too divergent, a remark which is interpreted by the listener as implying a very different image from his own is regarded as a personal threat and is resisted. Under these circumstances, conversation may split up into a number of different groups, each with a convergent image, but there is no tendency for the different images of the subgroups to converge.

This theory stresses the importance of the communication network in the development of common images. The larger an organization becomes, the more difficult is the maintenance of adequate "conversation"-twoway image modifying communications among the component parts. There is a tendency, therefore, for the organization to split up into "non-conversing groups"-each group conversing within itself but not conversing with other groups. Thus management becomes a group with much internal conversation and a converging image, and the labor force becomes another group with a different image. Much industrial conflict is a result of the differing public images of management and labor groups. It may be that one of the most important social functions of the labor movement is that it provides an intermediate group of labor leaders who participate in both groups and hence are able to act as intermediaries between them. The chaplain in the armed forces may perhaps have a rather similar role, participating in two potentially opposite and nonconversing groups-the armed forces and the church. The lot of the middlemen, however, is hard. Their personalities are in danger of being pulled apart by the conflict of roles in which they find themselves, or else they "sell out" to the dominant group. Thus we find labor leaders whose main function seems to be to make management decisions palatable to the rank and file and chaplains whose main concern is to whitewash the institution of war.

Implicit in the successful function of an organization is the notion of mutual acceptance of role images. If the participants in an organization do not accept the notion of the role structure, the organization is in danger of disintegrating. This does not mean that each individual must be satisfied with his own particular role. Indeed, unless there is some degree of dissatisfaction with the present role, an organization could never promote anyone, and too great satisfaction and harmony may actually lead to stagnation and decay through the failure of the "opensystem" aspects of organizational structure. There is a profound difference, however, between an ambition to aspire to another role and a rejection of the whole role structure as such. Thus union-management relations can be stable and harmonious only if both sides accept the role of the other. A revolutionary union, such as the old IWW, which rejects in toto the whole concept of a division of labor between employers and employed, cannot possibly enter into stable relations with the employer but must be in a state of constant conflict. Similarly, a revolutionary employer who is out to destroy the union and return to individual bargaining cannot establish stable relations with the union but again must be in constant warfare. Even two nations-two organizations whose main function, externally, is conflict culminating in war-can live peacefully together, like the United States and Canada, if each accepts fully the role of the other and if they share a reasonably common image of the mutual relationship. 


\section{The Theory of Organization and Conflict}

\section{THREE CONFLICT SITUATIONS}

Much more might be said on the subject of the theory of organization. In the interest of that conflict of space which besets every writer, however, we must now gather up the many strands of this paper to see whether the theory of organization, which we have presented here in bare outline, has fruitful applications to the theory of conflicts and their resolution. We must realize, of course, that there are many kinds of conflict situations. There is not a single concept of conflict, and therefore there cannot be a single theory of conflict. My own inquiries have led me to distinguish three different situations, each of which go by the name of conflict. We have first what Dr. Bernard calls "issue conflicts," which is what $I$, as an economist, might like to call "economic conflict." This is the situation in which a movement of change in a situation makes at least one party, in its own eyes, worse off and the other party better off. The theory of these situations has been elaborately developed in the theory of welfare economics, and I need not go into it here except to remark that, with two organizations, any given field can be divided into two sets, one which is called the "trading set," where movements are possible which benefit both parties, and the other, which is the "conflict set" (Edgeworth's "contract curve"), where a movement will benefit one party at the expense of the other.

\section{ECONOMIC CONFLICT}

An important dynamic principle emerges from this static theory, which might be called the "principle of the widening of the agenda." As long as the two parties are not in the conflict set, negotiation of a "trading" nature is possible, whereby both parties be- come better off. "Trading," however, inevitably moves the parties toward the conflict set and eventually lands them there. Once there, the only possibility is agreement or non-agreement; and if there is non-agreement, various rituals must be performed such as strikes, wars, etc., which will change the willingness to agree of one or both parties so that agreement becomes possibleassuming, that is, that the relationship cannot be avoided. Even if the parties are on the contract set in one field, however, they may get off it by widening the agenda to include variables which were not previously in discussion. Generally speaking, the wider the agenda, the greater the possibility for finding "trades," and the less chance there is of reaching an impasse on the conflict set. The principle of the widening of the agenda is exemplified in the multiplication of clauses in treaties and in union contracts. It is tempting to interpret the relative success of industrial relations as against the relative failure of international relations in terms of the greater flexibility of the agenda in unionmanagement negotiations as over against the hands-tied diplomat and the still more rigid soldier.

The contribution of organization theory to this part of conflict theory is to point out that it is not the "objective" situation which matters, but the subjective images of the participants, and that, therefore, the theory needs to be extended into the consideration of the dynamics of the formation and change of these images. Insofar as all issue conflicts involve utility, they are capable of resolution by changing value images as well as by a shift in the objective situation. It would be a grave error to think of issue conflicts as if they somehow involved brute facts, whereas psychological conflicts involved illusions. In the dynamics of issue conflicts especially, it is important to study 
the images of each party in its own mind and in the mind of the other.

\section{INTERACTION CONFLICT}

The second and the third type of conflict both fall under Dr. Bernard's class of psychological conflicts, and yet they represent, to my mind, entirely different situations. The second type is what might be called "interaction conflict" as typified in the arms race, in any process of mutually heightening hostility through the reaction of each party to the behavior of the other. The pioneering analysis of these processes by Lewis $F$. Richardson (4) perhaps merits entitling them "Richardson processes." In the Richardson model we postulate some measure of "hostility-friendliness" (as Richardson himself points out, these models apply just as well to the process of falling in love as they do to the arms races). Then we suppose that the increase in the hostility of each party is a function, first, of some constant term which represents the underlying "grievance," and, second, of the absolute level of hostility of the other party. This gives us two simultaneous differential equations. These may have an equilibrium solution (a "balance of power"), or they may be indefinitely explosive up to some boundary at which the system breaks down in war, strike, or divorcedepending on the nature of the parameters. The less "sensitive" the parties-the less the hostility of one increases at each level of hostility of the other-the more likely is a balance-of-power solution to be found. The model can be extended easily to more complex cases involving, for instance, such variables as "submissiveness."

The Richardson process is a very general phenomenon, observable in international relations, in industrial relations, and in family relations. It may be almost unrelated to any "issue conflict," though the process takes account of this possibility through the constant term in its functions. The contribution of the theory of organization to these processes seems to be to point out the importance of the perception problem. It is not the "objective" hostility of the parties which is important, but the perceived hostility, that is, the hostility of each as perceived by the other. Consequently, again, the pattern of image formation takes a foremost place in the general theory of these processes. What are the cues, for instance, by which hostility is perceived, and how may these cues be misinterpreted? One may introduce, as an essential element in the process, the predisposition to perceive hostility. This is unquestionably related to internal hostility (self-hatred). The greater this predisposition, of course, the more likely are we to find unstable Richardson processes set off. The Freudian theory of displacement and aggression fits nicely into the general picture at this point. The self-hater is more likely to get into Richardson processes of mutually increasing hostility than the well-adjusted self-lover. The wisdom of the great commandment to "love our neighbor as ourselves" is amply justified by this impressive body of theory!

\section{INTERNAL CONFLICT}

The third type of conflict situation is that described by Kurt Lewin (2) and Neal Miller (3) and might be described as the "quandary." This is the situation in which the individual (or organization) is incapable of making a decision because it is pulled (or pushed) in two opposite directions at the same time! This is a strictly internal conflict; it does not involve two parties but the motivational forces operating on a single party. It falls into quite a different category, therefore, from either issue conflicts or Richardson processes. It is, nevertheless, relevant to the wider concept, in that the internal conflicts may profoundly affect the conduct of external conflicts. Miller makes the extremely 
interesting suggestion that quandaries which result from opposing pulls or attractions are unstable; if the individual veers ever so slightly toward one side or the other, the side toward which he veers exerts a strong pull on him, and he soon goes over to it. Quandaries which result from opposing pushes or repulsions are stable; as we veer to one side, the push becomes stronger and pushes us back into the quandary. Buridan's ass between two bales of hay is unstable. The slightest variation toward one bale reinforces its pull, and he goes toward itreturning then, as someone has observed, to eat the other! Buridan's ass, on the other hand, between two equally repellent skunks would be in a position of agonizing stability. As he moved toward either skunk, its repellent force would increase and would push him back toward the other.

Insofar as internal conflict of this kind produces disorganization and self-hatred, it has an important bearing on two-party conflict, as we have seen. The proposition may be ventured that those who are motivated mainly by hatred (fleeing away from what they do not like rather than toward what they like) are likely to get into quandaries and to be racked with stable internal conflicts destructive to their internal organization. Because of this, they are also likely to get involved in Richardson processes of mutually increasing hostility and are also likely to be unable to adjust their value structures (rendered rigid by their very disorganization) in the resolution of issue conflicts. Those who are motivated by "love," on the other hand, who move toward what they like rather than away from what they do not like, will be able to resolve quandaries easily, will be unlikely to get into processes of mutually increasing hostility, and can afford to have flexible value images which will help them in getting out of issue conflicts (liking what they get, instead of getting what they like).

\section{Conflict Resolution}

I may offer one final word on conflict resolution. Perhaps the most important avenue of conflict resolution is simple avoidance. This is much neglected by the psychologists, though it is familiar enough to economists, and is indeed the basis for the economist's prejudice in favor of perfect competition. In a perfectly competitive market there is no conflict at all; if one arises, it is immediately avoided by switching to another buyer or another seller. It is only as markets become imperfect that conflict becomes important, as it becomes increasingly impossible to avoid particular relationships. The conflict between a professor and his dean is frequently resolved by a nice letter from another dean. In family life, divorce or separation represents conflict avoidance; here again the extreme (and inevitable) imperfection of the marriage market makes conflict in this area possibly more intense than in almost any other. In international relations, likewise, the impossibility of avoidance, especially in a world of few great powers, makes this particular solution inadmissible and forces the development of organizational solutions. Also in industrial relations, once labor is organized, avoidance becomes impossible; the individual worker can flee to another shop, but the union has to stay with the employer till death do them part.

If avoidance is impossible, the resolution of conflict depends on two factors: the reduction in the intensity of the conflict, on the one hand, and the development of overriding organizations which include both parties, on the other. The intensity of conflict can be reduced by a change in the value images of the parties toward "love" and away from "hate," by an expansion of the 
field into which organizations are growing, by a diminution of their expansion pressure, and so on. Overriding organizations can develop either through sheer conquest, in which one party is eliminated (making a desert and calling it peace), or through the development of images in both parties in which there is acceptance of the role of a larger organization. Organization theory is important here in pointing out the limiting factors on the size of organization. These limiting factors may prevent the rise of uniting organizations unless the functions of these organizations are severely limited. It is clear, for instance, that world government would prevent "international" war; it is possible, however, that its very size would cause it to fall apart and render it impotent to prevent the re-formation of "non-conversing groups," with the consequent danger of civil war. It is perhaps the chief function of organization theory to warn us against simple or formal solutions and to point out the richness and complexity of conflict situations and their roots in the image-forming process.

\section{R E F E E N CES}

1. Boundng, K. W. The Image. Ann Arbor: University of Michigan Press, 1956.

2. Lewin, K. Resolving Social Conflicts. New York: Harper \& Bros., 1948.

3. MILL.ER, N. E. "Comments on Theoretical Models, Illustrated by the Development of a Theory of Conflict Behavior," Journal of Personality, XXI (1956), 82-100.

4. Richardson, L. F. "Generalized Foreign Politics," British Journal of Psychology, Monograph Supplements, Vol. XXIII (1939).

5. Thompson, D. W. On Growth and Form. Cambridge: At the University Press, 1942. 